\title{
CHILD'S DENTAL AGE AS A BIOLOGICAL MARKER OF INDIVIDUAL DEVELOPMENT
}

\author{
Valentyn Makeev', Olha Isakova², Volodymyr Shybinskyy', Jakub Hadzik³, Anna Krupnyk² \\ 'Department of Prosthodontics, Lviv National Medical University, Ukraine \\ 2Deparment of Pediatric Dentistry, Lviv National Medical University, Ukraine \\ ${ }^{3}$ Department of Dental Surgery, Medical University of Wroclaw, Poland
}

\begin{abstract}
INTRODUCTION: Assessment of children's dental age is an important problem in pediatric dentistry, endocrinology, and orthodontics. Orthodontists, by comparing dental age with chronological age, can predict the schedule of treatment and choose the optimal treatment period. For pediatricians, is important to know dental maturity of children with certain diseases, whose treatment may be accelerated or postponed.

ОвJеCтIVEs: The objective of the study was to evaluate Cameriere's method of dental age assessment technique as a biomarker of child's individual development.

MATERIAL AND METHODs: The study included 108 children, aged between 6 and 13 years, in whom chronological age was compared with dental age assessed by Cameriere's method. The determined age was compared with the chronological age of children.

RESULTs: It was found that the average chronological age among the surveyed boys $(n=65)$ was $9.97 \pm 2.27$ years, and the age estimated based on Cameriere's method was $9.77 \pm 2.24$ years. Similarly, among the girls $(n=43)$, the mean chronological age was $10.05 \pm 2.15$ years, and the estimated age was $10.30 \pm 2.17$. Statistical analysis of correlation of the dental and calendar (chronological) ages revealed a certain percentage of children who did not fit into general average description and were beyond reliable data.

ConcLusions: Determination of dental age as a marker of biological maturity, in some cases, may indicate a deviation from the average results. Such children need individual correction of standard treatment regimens, involving timing of treatment, degree of biological maturity, and body's readiness for a medical intervention.
\end{abstract}

KEY WORDS: orthodontics, dental age, age estimation, Cameriere's formula, Cameriere's method.

J Stoma 2020; 73, 5: 246-253

DOI: https://doi.org/10.5114/jos.2020.100531

\section{INTRODUCTION}

Currently, social progress steadily depletes the biological and functional human reserves. The processes of adaptation are violated, and maladaptive behavior develops, which results in a pathology. One of the human adaptation indicators is the biological age (BA) [1].
BA is defined as the conformity of individual morphological and functional levels to a certain average norm of a population and reflects the rate of age-related changes and adaptive capabilities of the organism [2-5].

BA should be considered to predict individual human health. It allows assessing the degree of conformity of body's biological condition to the calendar age
ADDRESS FOR CORRESPONDENCE: Jakub Hadzik, Dental Surgery Department, Medical University of Wroclaw, Krakowska 26, 50-425 Wrocław, Poland, e-mail: jakub.hadzik@umed.wroc.pl

RECEIVED: 13.06.2020 • ACCEPTED: 01.09.2020 • PUBLISHED: 30.10 .2020 
of a person and indicates the rate of development and biological aging that affect the functioning of basic life support systems and life expectancy. Discrepancies between calendar and biological ages allow assessing the intensity of maturation, aging, and functional capabilities of an individual [6-8].

Chronological or calendar age is defined as the period of time between birth and research, expressed as the number of years, months, and days that have passed. The biological age of a child is an individual development pace of a specific child, which may not match his/her calendar age. Biological age is determined by morphometric, physiological, metabolic, and immunological characteristics that are close to the indicators of average age. The biological age of a child is based on the dominance of average biological age of individual's tissues, organs, and body systems, with minor deviations determining the harmonious or disharmonious physical and neuro-psychical development of the child. However, the developmental age is defined as the biological maturity of an organism and the level of child's systemic development. The age of development includes morphological age, age of secondary sexual characters, bone (skeletal) age, and dental age $[9,10]$.

Dental age is one of the few indicators of a child's developing physiology and, consequently, one of the important factors for determining the biological age of a patient. Dental age was firstly described in the $19^{\text {th }}$ century and is still the object of research [11]. Its estimation is important for decision-making regarding diagnostic algorithms and treatment options in some fields of medicine, such as conservative dentistry, orthodontics, pediatrics, or endocrinology as well as for forensic medicine purposes [12-14]. Popular method for estimating a dental age is radiographic study of a child's left wrist or mesial cartilage of the clavicle epiphysis $[15,16]$. However, these skeletal methods feature some drawbacks, given the variability in bone maturation affected by environmental factors and lifetime X-ray load in a child's body.

The method for determining the age based on calcification rate is more controlled by genes and is almost independent of environmental factors [17-19].

The most common method for estimating the age based on determining morphological parameters of teeth from X-ray images of children's teeth was published in 1973 by Demirjian et al. and subsequently modified by other authors [20]. In 2006, Cameriere presented another new technique, which was introduced as a survey of Italian children. This method, which is based on measuring the open tops of permanent teeth of the left lower jaw, became the basis of this research [21-26].

The Cameriere's method based on the detection of physiological changes (root calcification rate) in permanent teeth of children using X-ray was the foundation of a similar research in Ukraine among children of a particular region.

\section{OBJECTIVES}

The primary objective of this research was to compare the age of children determined by the Cameriere's method with their chronological age to assess the statistical reliability and individual differences in the selected age group of children from a particular region of Ukraine. Additional aim of this study was to increase the efficiency of diagnostics and treatment of dental system pathologies in children during the period of change in occlusion by establishing dental age assessment technique based on the Cameriere's method as a biomarker of child's individual development.

\section{MATERIAL AND METHODS}

This research examined orthopantomograms of children (boys and girls), aged between 6 and 13 years from Lvov and Lvov region, Ukraine, who were selected by criteria, such as age, gender, lack of agenesis or extraction of permanent teeth in the lower left quadrant, excluding the third molars.

A questionnaire was developed to record children's data, and a standardized format for entering the indicators from orthopantomograms (OPG) was established.

Clinical examination of patients was conducted at $\mathrm{Pe}$ diatric Dentistry Department of the Danylo Halytsky National Medical University of Lvov. The study was performed in compliance with the ethical principles for conducting medical research involving human subjects, approved by the Helsinki Declaration (order of Ministry of Health of Ukraine No. 690 from 23 September 2009) as well as the conclusion of the Commission on Ethics of Scientific Research, Experimental Development, and Academic Papers of the Danylo Halytsky National Medical University of Lvov, according to protocol No. 10, dated 16 December 2019.

For the first part of research, orthopantomograms of 108 children, 6-13 years old were examined. The orthopantomograms were recorded during a period of mixed occlusion in children's X-ray examination, which were conducted due to various reasons (orthodontic, paradontologic, etc.). The exclusion criteria were incomplete dental history, previous orthodontic treatment, pronounced systemic diseases, and congenital anomalies as well as incomplete germs of permanent teeth, except for the $3^{\text {rd }}$ molars. The objective of first part of the research was to estimate the calendar age of a child and his/her dental age determined by the Cameriere's method, using the formula of linear regression modified by the author in the process.

To implement this phase, all patients were subdivided into four groups according to age and sex (Table 1).

Among the studied patients, boys accounted for $60.2 \%$ and girls for $39.8 \%$. All children were divided into age groups, such as 6-7, 8-9, 10-11, and 12-13 years old, subject to the preservation of proportional and harmonious distribution by both sex and age. 
TABLE 1. Age and sex distribution among the studied children

\begin{tabular}{|l|c|c|c|}
\hline Age groups & \multicolumn{2}{c}{ Sex } & Total \\
& $\begin{array}{c}\text { Males } \\
\boldsymbol{n}(\%)\end{array}$ & $\begin{array}{c}\text { Females } \\
\boldsymbol{n}(\%)\end{array}$ & $\boldsymbol{N}(\%)$ \\
\hline $6-7$ & $16(14.8)$ & $7(6.5)$ & $23(21.3)$ \\
\hline $8-9$ & $18(16.7)$ & $16(14.8)$ & $34(31.5)$ \\
\hline $10-11$ & $14(13.0)$ & $8(7.4)$ & $22(20.4)$ \\
\hline $12-13$ & $17(15.7)$ & $12(11.1)$ & $29(26.8)$ \\
\hline Total & $65(60.2)$ & $43(39.8)$ & $108(100)$ \\
\hline
\end{tabular}

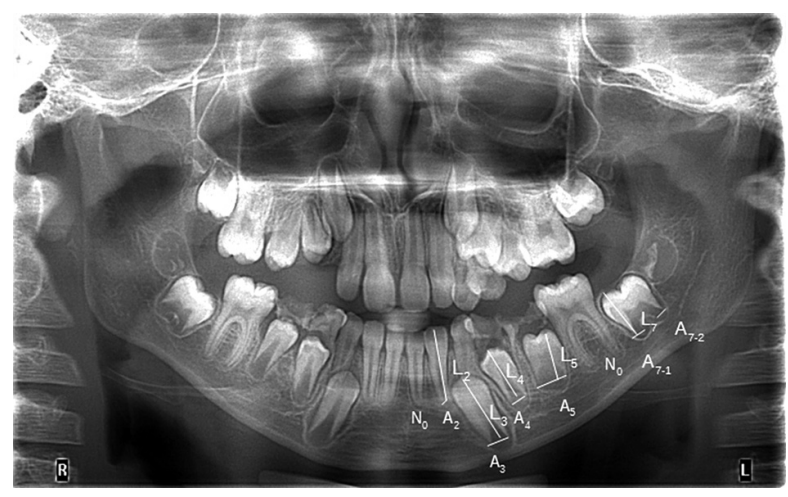

FIGURE 1. Orthopantomogram of a boy 9 years and 8 days old

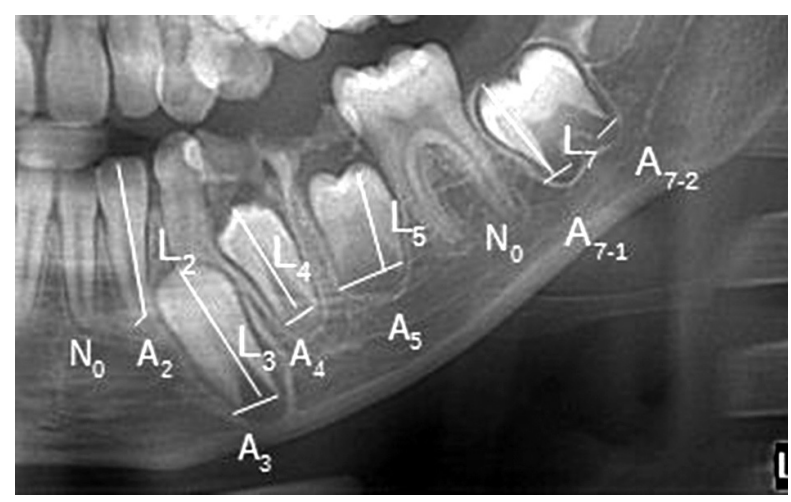

FIGURE 2. Left mandibular segment

Orthopantomograms were used to study the area of lower seven teeth on the left by the Cameriere's method to determine the individual root coefficient of each permanent tooth $(\mathrm{A} / \mathrm{L}$ ratio) from the lower left quadrant (teeth $31,32,33,34,35,36,37$ ), where $L$ is the length of the tooth, and $A$ is the width of open top of the tooth root, that is the distance between the extreme points of root walls on the open top (Figure 1).

The calculation method was as follows. The lower left segment, i.e., the teeth of lower jaw in the $3^{\text {rd }}$ sector $(31,32,33,34,35,36,37)$ were the focus of orthopantomogram analysis. Third molars and their germs were not considered in the research, regardless of their presence or absence. A conventional perpendicular line drawn from the extreme point of each crown of a permanent tooth (or its germ) to the line connecting the extreme points of open top of a permanent tooth (or its germ) root in the lower left segment was measured. The length of this line was denoted as $L$. Next, the width of open root top of each tooth was measured, and this value was denoted as $A$. In case a tooth with multiple roots, the width of open top of each root was measured, and the results were summarized.

$A$ and $L$ values were specified according to the numbering of each tooth. For example, the values of central incisor were denoted as L1 and A1, lateral incisor as L2 and $A 2$, etc. In multirooted teeth, when the open tops were measured, the value for each root top was marked with an additional serial number after denoting the order of tooth in this segment, i.e. the roots of tooth 37 were denoted as A7.1 (mesial root) and A7.2 (distal root). The value of A6 in this case was equal to the total of A7.1 and A7.2 (A7 = A7.1 + A7.2). These values for the roots of second lower molar or other teeth with more than one root in a particular child was numbered similarly. Teeth with closed top were denoted as $\mathrm{N}_{0}$. The measurements are shown in Figure 2.

To perform calculations using the Cameriere's method, it was required to determine the ratio of the size of open top of each tooth $(A)$ to its length $(L)$. This ratio was indicated as $X$ and the serial number for each examined tooth was $\mathrm{X}_{1}, \mathrm{X}_{2}, \mathrm{X}_{3}$, etc. Accordingly, the formula to determine $X$ value for the canine was as follows: $\mathrm{X}_{3}=\mathrm{A}_{3} / \mathrm{L}_{3}$, and for the second molar: $\mathrm{X}_{7}=\left(\mathrm{A}_{7-1}+\mathrm{A}_{7-2}\right) / \mathrm{L}_{7}$.

Therefore, having made the required measurements, we obtain the following calculations:

$$
\begin{aligned}
& \mathrm{X}_{1}=\mathrm{N}_{0} ; \\
& \mathrm{X}_{2}=\mathrm{A}_{2} / \mathrm{L}_{2}=0.35 / 3.8=0.092 ; \\
& \mathrm{X}_{3}=\mathrm{A}_{3} / \mathrm{L}_{3}=0.95 / 3.9=0.244 ; \\
& \mathrm{X}_{4}=\mathrm{A}_{4} / \mathrm{L}_{4}=0.8 / 3.1=0.258 ; \\
& \mathrm{X}_{5}=\mathrm{A}_{5} \mathrm{~L}_{5}=1.4 / 2.6=0.538 ; \\
& \mathrm{X}_{6}=\mathrm{N}_{0} ; \\
& \mathrm{X}_{7}=\mathrm{A}_{7} / \mathrm{L}_{7}=1.0 / 2.7=0.37 \\
& \text { where } \mathrm{A}_{7}=\mathrm{A}_{7-1}+\mathrm{A}_{7-2} .
\end{aligned}
$$

There are many modifications of the Cameriere's linear regression formula that have been developed by scientists from different countries for individually selected populations of children. The need for modification was due to abnormalities of children's maxillofacial area structure as well as features of its formation in children residing in a certain region. That is, for almost every other region or country of residence of studied children, the formula was modified in the view of peculiarities typical for a region. Some scientists have introduced additional factors for each sex, in the presence or absence of premolars, number of examined girls or boys, etc. After a survey of children in Lvov and Lvov region, the Cameriere's linear regression formula was amended and clarified as follows: 
TABLE 2. Comparison of chronological age and dental age (by the Cameriere method) among the studied children

\begin{tabular}{|c|c|c|c|c|c|c|}
\hline Method & $n$ & $M \pm \sigma$ & Min & Max & $t$-value & $p$-value \\
\hline \multicolumn{7}{|l|}{ Males } \\
\hline Chronological age & 65 & $9.97 \pm 2.27$ & 6.15 & 13.74 & \multirow{2}{*}{0.51} & \multirow{2}{*}{$\begin{array}{c}0.61 \\
\text { NS }\end{array}$} \\
\hline Dental age & 65 & $9.77 \pm 2.24$ & 6.15 & 13.27 & & \\
\hline \multicolumn{7}{|l|}{ Females } \\
\hline Chronological age (years) & 43 & $10.05 \pm 2.15$ & 6.10 & 13.56 & \multirow{2}{*}{0.53} & \multirow{2}{*}{$\begin{array}{c}0.60 \\
\text { NS }\end{array}$} \\
\hline Dental age (years) & 43 & $10.30 \pm 2.17$ & 6.08 & 13.32 & & \\
\hline
\end{tabular}

NS - no significant

Dental age $=9.402+0.663 \times \mathrm{N}_{0}-0.711 \times s-0.106 \times$ $\times \mathrm{s} \times \mathrm{N}_{0}$,

where $s$ is the sum of ratios of the tooth length and the width of open top of the root of seven examined teeth on the lower left part of the jaw, i.e., $s=X_{1}+X_{2}$ $+\mathrm{X}_{3}+\mathrm{X}_{4}+\mathrm{X}_{5}+\mathrm{X}_{6}+\mathrm{X}_{7}$. In this case, $s$ will be as follows: $s=1.502 . N_{0}$ is the number of teeth with the closed top of root of a permanent tooth in the lower left segment of a child under study. If there was no permanent tooth with a closed top in this segment, then $\mathrm{N}_{0}=1$ in the formula. If the $\mathrm{A} / \mathrm{L}$ ratio $<0.8$, then such a tooth shall be denoted as $\mathrm{N}_{0}$.

The calculation of a child's dental age according to his/ her orthopantomogram (Figures 1 and 2) using the linear regression modified for this region was as follows:

Dental age $=9.402+0.663 \times 2-0.711 \times 1.502-0.106$ $\times 1.502 \times 2=9.34$, which means that in that calculation, the dental age determined by this method was 9 full and 0.34 years. Next, the number of full months and days was calculated as follows: $0.34 \times 12$ (number of months in a calendar year) $=4.08$, which means 4 full and 0.08 months. In the calculations, the length of month was assumed as 30 calendar days. Therefore, further calculations were as follows: $0.08 \times 30=2.4$ days, rounded up to 2 days, according to the mathematical rules.

Obtained result of dental age calculation according to the modified Cameriere's linear regression formula for this child was 9 years, 4 months, and 2 days. Hence, the difference from the chronological age was only 3 months and 24 days.

\section{RESULTS}

In the analysis of results, it was found that the average chronological age among the boys under study $(n=65)$ was $9.97 \pm 2.27$ years, and by the Cameriere's method, it was $9.51 \pm 2.21$ years. The estimation using Student's $t$-test did not reveal a significant difference between the data $(p=0.61)$. Similarly, the average chronological age among the studied girls was $10.05 \pm 2.15$ years, and by the value determined by the Cameriere's method, it was $10.30 \pm$ $2.17(p=0.60)$. The analysis is presented in Table 2 .

Still, the correlation analysis revealed a statistically
TABLE 3. Intergroup correlation between chronological age and Cameriere's age (dental age) among boys and girls

\begin{tabular}{|l|c|c|}
\hline Parameter & Intergroup correlation value, $\boldsymbol{r}$ & $\boldsymbol{p}$-value \\
\hline General group & 0.961 & $<0.0001$ \\
\hline Males & 0.967 & $<0.0001$ \\
\hline Females & 0.965 & $<0.0001$ \\
\hline
\end{tabular}

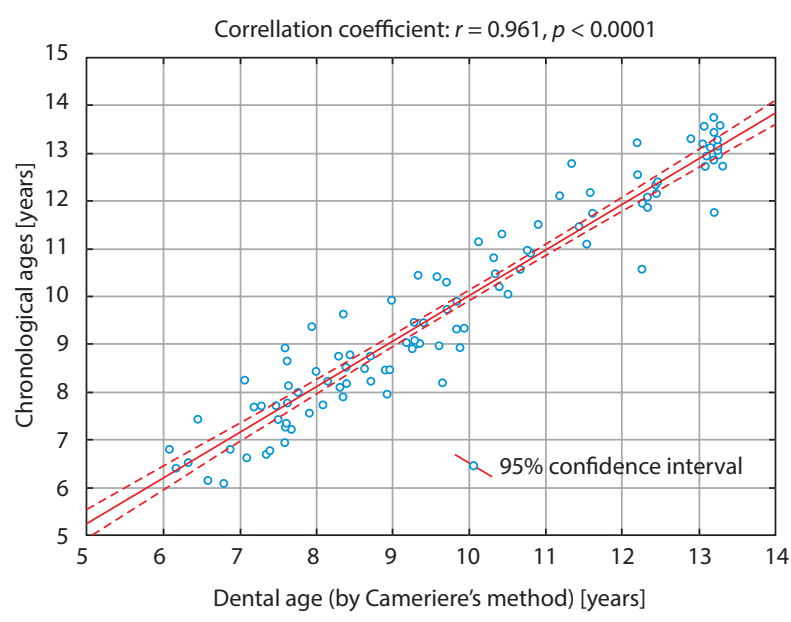

FIGURE 3. Correlation between the chronological age and dental age (determined by the Cameriere's method) in the study group $(n=108)$

significant proportional relationship between chronological age and age calculated by the Cameriere's method both in the general group $(r=0.961, p<0.0001)$ and among the boys $(r=0.967, p<0.0001)$ and the girls $(r=0.965, p<0.0001)$ (Table 3).

Graphs presented in Figures 3-5 show a close distribution of the obtained indicators to the central axis and a narrow $95 \%$ confidence interval, which suggests a very strong correlation between the two methods of estimating age in both the general group and among the boys and girls.

Further analysis among the boys under study showed that in all age categories, the age values obtained by the two methods did not differ statistically $(p>0.05)$ (Table 4). In all age subgroups, direct medium strength or strong significant $(p<0.05)$ correlations between chrono- 


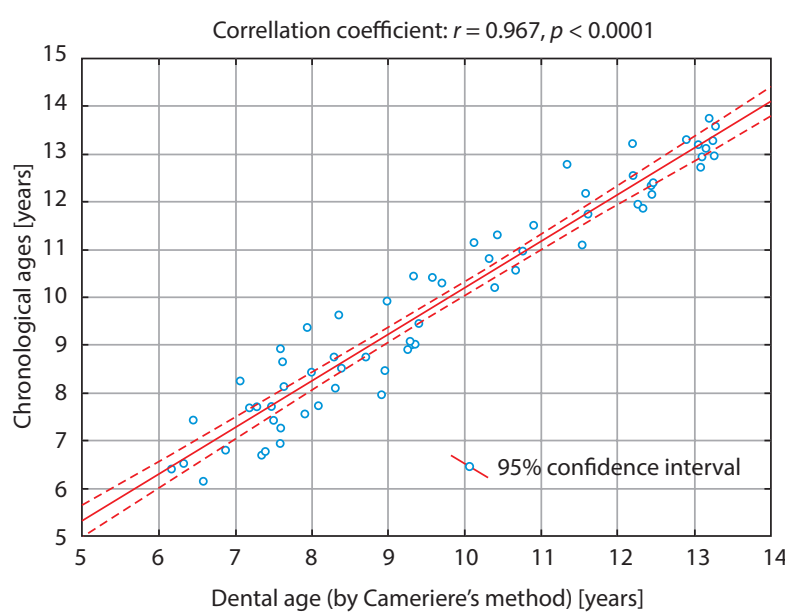

FIGURE 4. Correlation between the chronological age and dental age (determined by the Cameriere's method) among the boys under study $(n=65)$

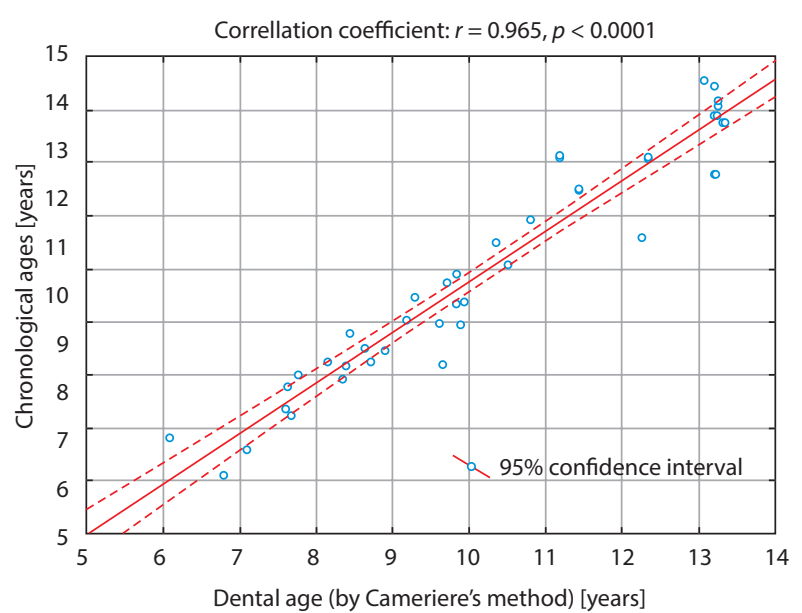

FIGURE 5. Correlation between the chronological age and dental age (determined by the Cameriere's method) among the girls under study $(n=43)$

TABLE 4. Comparison of the chronological age and age determined by the Cameriere's method (dental age) among the boys under study in different age groups (years)

\begin{tabular}{|c|c|c|c|c|c|}
\hline Age group & $n$ & $\begin{array}{c}\text { Chronological age, } \\
\qquad \pm \sigma\end{array}$ & $\begin{array}{l}\text { Age by Cameriere's method, } \\
\qquad M \pm \sigma\end{array}$ & $t$-value & $p$-value \\
\hline $6-7$ & 16 & $7.17 \pm 0.56$ & $7.28 \pm 0.71$ & 0.50 & 0.62 \\
\hline $8-9$ & 18 & $8.85 \pm 0.51$ & $8.46 \pm 0.73$ & 1.86 & 0.07 \\
\hline $10-11$ & 14 & $11.02 \pm 0.59$ & $10.71 \pm 0.94$ & 1.06 & 0.30 \\
\hline $12-13$ & 17 & $12.92 \pm 0.48$ & $12.71 \pm 0.61$ & 1.14 & 0.26 \\
\hline Total & 65 & $9.97 \pm 2.27$ & $9.77 \pm 2.24$ & 0.51 & 0.61 \\
\hline
\end{tabular}

TABLE 5. Comparison of the chronological age and age determined by the Cameriere's method (dental age) among the girls under study in different age groups (years)

\begin{tabular}{|c|c|c|c|c|c|}
\hline Age group & $n$ & $\begin{array}{l}\text { Chronological age, } \\
\qquad \mathrm{M} \pm \sigma\end{array}$ & $\begin{array}{l}\text { Age by Cameriere's method, } \\
\qquad M \pm \sigma\end{array}$ & $t$-value & $p$-value \\
\hline $6-7$ & 7 & $7.10 \pm 0.64$ & $7.31 \pm 0.73$ & 0.55 & 0.59 \\
\hline $8-9$ & 16 & $8.83 \pm 0.60$ & $9.12 \pm 0.70$ & 1.25 & 0.22 \\
\hline $10-11$ & 8 & $11.07 \pm 0.65$ & $11.65 \pm 1.14$ & 1.25 & 0.23 \\
\hline $12-13$ & 12 & $12.74 \pm 0.54$ & $12.74 \pm 0.80$ & 0.00 & 1.00 \\
\hline Total & 43 & $10.05 \pm 2.15$ & $10.30 \pm 2.17$ & 0.53 & 0.60 \\
\hline
\end{tabular}

logical age and age determined by the Cameriere's method were found (Table 6).

Similarly, the analysis among the girls under study revealed that in all age categories, the age values obtained by the two methods did not differ statistically $(p>0.05)$ (Table 5). Moreover, direct strong significant $(p<0.05)$ correlations between chronological age and age determined by the Cameriere's method were determined in all age subgroups (Table 6).

Power analysis was performed in all groups and subgroups. A power level of 0.8 and more was obtained in all cases, considering a total sample size.
The calculations were performed using RStudio v. 1.1.442 and R Commander v.2.4-4. Power analysis was performed using GPower 3.1.

\section{DISCUSSION}

After statistical processing of the data obtained by the Cameriere's method, for most children (>90\%), the dental age was not statistically different from the chronological age, and there was a strong positive correlation between them. This suggests the possibility of using the Camerie- 
re's method to determine the dental age in pediatric dentistry, forensic practice as well as in the other branches of medicine. The Cameriere's linear regression formula, modified in the course of this study, showed high accuracy of the results obtained among the pediatric population from Galicia (Ukraine).

Exploring the deliverables of statistical analysis corresponding with a child's dental age to his/her calendar age among 6-13 years old children, we revealed a certain percentage of children in each age group who did not fit into the overall average statistical description, and were beyond the valid data. For example, in the group of 8-9 years old boys, in 4 of 18 children, the difference between the estimated dental age and calendar age was more than a year, even though for the remaining boys in the group, this difference did not surpassed 12 months.
TABLE 6. Intergroup correlation values among the boys and girls in different age categories

\begin{tabular}{|c|c|c|c|}
\hline Parameter & $\boldsymbol{n}$ & \multicolumn{1}{|c|}{ Intergroup correlation value, $\boldsymbol{r}$} & $\boldsymbol{p}$-value \\
\hline Males & 65 & 0.967 & $<0.0001$ \\
\hline $6-7$ & 16 & 0.697 & 0.003 \\
\hline $8-9$ & 18 & 0.473 & 0.047 \\
\hline $10-11$ & 14 & 0.833 & 0.0002 \\
\hline $12-13$ & 17 & 0.620 & 0.008 \\
\hline Females & 43 & 0.965 & $<0.0001$ \\
\hline $6-7$ & 7 & 0.759 & 0.048 \\
\hline $8-9$ & 16 & 0.748 & 0.001 \\
\hline $10-11$ & 8 & 0.738 & 0.037 \\
\hline $12-13$ & 12 & 0.763 & 0.004 \\
\hline
\end{tabular}

TABLE 7. Comparative analysis of variations corresponding to dental age and calendar age among boys of different age groups

\begin{tabular}{|c|c|c|c|c|c|}
\hline \multirow[t]{2}{*}{ Age group } & \multirow{2}{*}{$\begin{array}{c}\text { Total children, } \\
n\end{array}$} & \multicolumn{2}{|c|}{ Variations within 0-12 months } & \multicolumn{2}{|c|}{ Variations within 12-18 months } \\
\hline & & $n$ & $\%$ & $n$ & $\%$ \\
\hline $6-7$ & 16 & 16 & 100 & 0 & 0 \\
\hline $8-9$ & 18 & 14 & 77.8 & 4 & 22.2 \\
\hline $10-11$ & 14 & 11 & 78.6 & 3 & 21.4 \\
\hline $12-13$ & 17 & 15 & 88.2 & 2 & 11.8 \\
\hline Total & 65 & 56 & 86.2 & 9 & 13.8 \\
\hline
\end{tabular}

TABLE 8. Comparative analysis of variations corresponding to dental age and calendar age among girls of different age groups

\begin{tabular}{|c|c|c|c|c|c|}
\hline \multirow[t]{2}{*}{ Age group } & \multirow{2}{*}{$\begin{array}{c}\text { Total children, } \\
n\end{array}$} & \multicolumn{2}{|c|}{ Variations within 0-12 months } & \multicolumn{2}{|c|}{ Variations within $12-18$ months } \\
\hline & & $n$ & $\%$ & $n$ & $\%$ \\
\hline $6-7$ & 7 & 7 & 100 & 0 & 0 \\
\hline $8-9$ & 16 & 15 & 93.8 & 1 & 6.2 \\
\hline $10-11$ & 8 & 8 & 100 & 0 & 0 \\
\hline $12-13$ & 12 & 12 & 100 & 0 & 0 \\
\hline Total & 43 & 42 & 97.7 & 1 & 2.3 \\
\hline
\end{tabular}

TABLE 9. Comparative analysis of variations corresponding to dental age and calendar age among all children under study of different age groups in absolute values and percentage

\begin{tabular}{|l|c|c|c|c|c|}
\hline \multirow{2}{*}{ Age group } & Total children, & \multicolumn{2}{c}{ Variations within 0-12 months } & \multicolumn{2}{c|}{ Variations within 12-18 months } \\
\hline & $\boldsymbol{n}$ & $\boldsymbol{n}$ & $\mathbf{n}$ & 0 & 0 \\
\hline $6-7$ & 23 & 23 & 100 & 5 & 14.7 \\
\hline $8-9$ & 34 & 29 & 85.3 & 3 & 18.2 \\
\hline $10-11$ & 22 & 18 & 81.8 & 2 & 6.9 \\
\hline $12-13$ & 29 & 27 & 93.1 & 10 & 9.3 \\
\hline Total & 108 & 98 & 90.7 & & $\boldsymbol{n}$ \\
\hline
\end{tabular}


The exceptions found in the other age groups are of particular interest in this study, since they indicate individual features in a development of a specific child who exceeds or lingers behind its chronological age. In other words, dental age as a marker of biological maturity of a child's body indicates a deviation from the average results. Such children need particular correction of standard treatment regimens and treatment periods considering their biological maturity and body readiness for a medical interventions (Tables 7 and 8).

Based on the comparative analysis of variations corresponding to the dental age and the calendar age of 6-13 years old children, the percentage of children whose dental age did not correspond to the calendar (chronological) age was obtained. For the boys of all groups, it was $13.8 \%$ and for the girls, only $2.3 \%$, respectively. The largest deviation was observed in the age group of 8-9 years old for both the boys and girls, but for the boys, this percentage was $22.2 \%$ as compared to $6.2 \%$ of the girls.

The closest indicators of chronological and dental age determined by the Cameriere's method for the boys were found in the age group of 6-7 years old.

In general, a comparative analysis of the results revealed a high percentage (within 12 months) of correspondence of the dental age to the chronological age (Table 9).

Determination of dental age in this research showed the accuracy of data obtained by the Cameriere's method as well as the effectiveness of modifications of the Cameriere's linear regression formula made by the authors in the course of the study in a specific group of children from Lvov region of Ukraine. It should also be noted that in practically each age group of children, among both the boys and girls, there were single individuals who did not fit in the average statistics and were beyond their limits. Finally, the variation between calendar and dental age within 18 months was revealed in $9.3 \%$ of children. Such cases are of greatest interest for this research as individuals requiring a special approach in the course of diagnostics and treatment, considering the difference in their dental and chronological age and, consequently, lingering or surpassing body development.

\section{CONCLUSIONS}

The analysis of the results clearly shows that the largest number of deviations of dental age values from the chronological age is recorded at the beginning of an active process of tooth change, restructuring, and formation of the bone tissue. The first visits to an orthodontist and evaluation of the tooth-jaw apparatus in accordance with the age are carried out during this period. At this time, it is very important to evaluate the individual physiological development of a child in accordance with its chronological age, and to determine the optimal period for a particular treatment. If the dental age as a child's biological maturity indicator is considered, the plan of required medical procedures can be adjusted, considering the child's biological age and its development peculiarities. Planning a protocol and timing of treatment based on the physiological development of a specific child would certainly provide better results as compared to a generalized approach.

Therefore, the dental age determination as one of the markers of the body's biological maturity is indeed required for an individualized approach in treatment of children.

\section{CONFLICT OF INTEREST}

The authors declare no potential conflicts of interest with respect to the research, authorship, and/or publication of this article.

\section{References}

1. Apanasenko GL. Individual health: theory and practice. In: Introduction to the theory of individual health: a monograph. Apanasenko GL, Popova LA (eds.). Kiev: Medkniga; 2011, p. 108.

2. Belozerova LM. Methodology of studying age changes. J Clin Gerontol 2002; 8: 3-7.

3. Belozerova LM. Method of determining the biological age by spirography. J Clin Gerontol 2006; 12: 53-56.

4. Anisimov VN. Molecular and Physiological Mechanisms of Aging. St. Petersburg: Publishing House Nauka; 2008, p. 481.

5. Oeppen J, Vaupel JW. Broken limits to life expectancy. Science 2002; 296: 1029-1031.

6. Hrybok NM, Prots RO. Comparative analysis of biological age of students of pedagogical university. Health Sports Rehabilitation 2017; 3: 3-10.

7. Voitenko VP, Turner AB, Rudaya ES. Methods for determining the biological age. Questions of Gerontology 1989; 11: 9-16.

8. Markina LD. Determination of human biological age by the method of Voitenko VP: Allowance for independent work of medical students and psychologists Vladivostok; 2001, p. 29.

9. Knychalska-Karwan Z. Collection of dental indicators, classifications and tests. Lublin: Czelej; 2010.

10. Olczak-Kowalczyk D, Szczepańska J, Kaczmarek U. Modern dentistry of developmental age. Otwock: Med Tour Press; 2017.

11. Hubert E. Development of children with cleft primary and secondary palate. Stomatol Time 1986; 39: 519-524.

12. Demirjian A, Goldstein H, Tanner JM. A new system of dental age assessment. Hum Biol 1973; 45: 211-227.

13. Schuster G, Lermer W, Witt E. Using the internet for teaching orthodontic X-ray analysis. J Orofac Orthop 2002; 63: 163-169.

14. Otocki P. Determination of individual age based on teeth. Przegl Antropol 1988; 54: 65-82.

15. Schmeling A, Schulz R, Reisinger W, Muhler M, Wernecke KD, Geserick G. Studies on the time frame for ossification of the medial clavicular epiphyseal cartilage in conventional radiography. Int J Legal Med 2004; 118: 5-8.

16. Schulz R, Mühler M, Mutze S, Schmidt S, Reisinger W, Schmeling A. Studies on the time frame of ossification of the medial epiphysis of the clavicle as revealed by CT scans. Int J Legal Med 2005; 119: 142-145.

17. Nolla C. The development of permanent teeth. J Dent Child 1960; 27: 254.

18. Moorres CFA, Fanning EA, Hunt EE. Age variation of formation stages for ten permanent teeth. J Dent Res 1963; 42 : 1490.

19. Gleiser I, Hunt EE. The permanent mandibular first molar; its calcification, eruption, and decay. Am J Phys Anthropol 1995; 13: 253-283. 
20. Demirjian A, Goldstein H, Tanner JM. A new system of dental age assessment. Hum Biol 1973; 45: 211-227.

21. Bagh T, Chatra L, Shenai P, et al. Age estimation using Cameriere's seven teeth method with indian specific formula in south indian children. Int J Adv Health Sci 2014; 1: 2-4.

22. Cameriere R, Ferrante L, Cingolani M. Age estimation in children by measurement of open apices in teeth. Int J Legal Med 2006; 120: 49-52.

23. Cameriere R, Ferrante L, Cingolani M. Age estimation in children by measurement of open apices in teeth: a European formula. Int J Legal Med 2007; 121: 449-553.

24. Rai B, Anand SC. Tooth developments: an accuracy of age estimation of radiographic methods. World J Med Sci 2006; 1: 130-132.

25. Rai B, Anand SC. Age estimation in children from dental radiograph: a regression equation. Int J Biol Anthropol 2008; 1: 2.

26. Jamroz GMB, Kuijpers-Jagtman AM, Hof MA, Katsaros C. Dental maturation in short and long facial types: is there a difference? Angle Orthodontist 2006; 76: 768-772. 